\title{
Sehnsüchte - Anmerkungen zur romantischen Idee «Familie» in Deutschland
}

\author{
ANDREAS HALLLN \\ Berlin
}

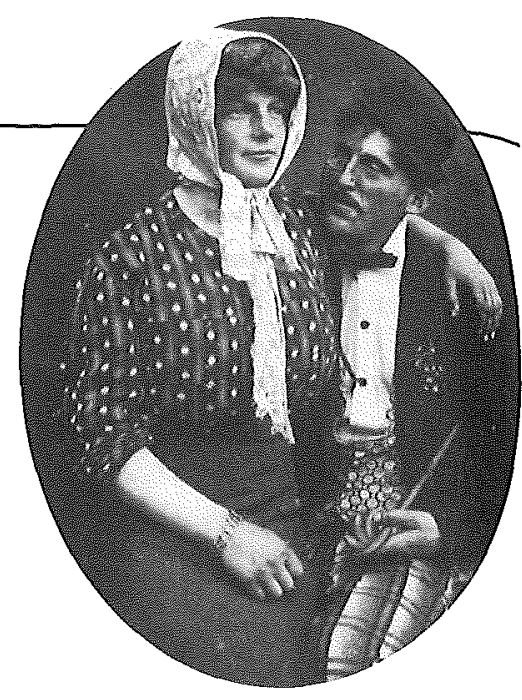

\section{Anmerkung 1}

Sehnsucht Familie

Nach der letzren Schell-Studie «Jugend 2002» rangiert unter der Rubrik wichtigste

Wertorientierung die

«Familie» auf Platz drei.

Wunsch und Wirklichkeit

liegen aber teils weit

auseinander: In deutschen

Großstädten wie Berlin,

Hamburg, Köln oder

München werden

$50 \%$ der Haushalte von

Singles bewohnt. Tendenz

steigend.

\section{Anmerkung 2 \\ Image}

Familien haben in

Deutschland laut dem

Meinungsforschungsinstitut

Allensbach ein Imageproblem.

Öffentliche und

veröffentlichte Meinung

kultivieren ein Bild von

«Kinder $=$ Armut $»$.

\section{Anmerkung 3 \\ Fehlanzeige}

Ebenfalls Allensbach stellte

2004 fest, dass ein Drittel der

Frauen in Deutschland keine

Kinder wünschen. $44 \%$ von

ihnen ergänzten, ihnen fehle

hierzu der geeignete Partner.

\section{Anmerkung 4}

Glück

Nach einer Umfrage des

Bundesverbandes der
Deutschen Banken schätzen

sich kinderlose Paare

glücklicher und optimistischer

ein als Eltern. Elternglück

stellt sich nach der

betreffenden Studie erst mit

erwachsenen Kindern ein.

\section{Anmerkung 5 \\ Unglïck}

Die Familie schafft

Geborgenheit. Aber auch

Gewalt: Sexuelle Gewalt wird weniger im tiefen Wald oder dunklen Gassen ausgeübt. Jugendliche werden zu $75 \%$ im familiären Umfeld sexuell missbraucht. 20.000 Anzeigen werden hierzu jährlich in

Deutschland erstattet. Die

Dunkelziffer schätzen

Experten auf drei- bis fünfmal so hoch. Demnach werden täglich bis zu 275 Jugendliche im familiären Umfeld missbraucht.

\section{Anmerkung 6 \\ Fiktion}

Geschichten, in denen Kinder ohne Eltern agieren, gehören bei Kindern und Erwachsenen zu den Bestsellern. Siehe Pippi Langstrumpf oder Harry Potter:

\section{Anmerkung 7 \\ Die gute alte Groffamilie}

Bis ins 19. Jahrhundert hinein lernten viele Enkelkinder ihre Großeltern nie kennen, weil diese in Mitteleuropa selten älter als 35 Jahre wurden. Die Altersversorgung ließen sich die Eltern aus Bauern- und Handwerkerfamilien von ihren Kindern stets vertraglich zusichern.

\section{Anmerkung 8 \\ Solidarität zwischen}

den Generationen

Ein Viertel der Großeltern unterstützen heute ihre Enkel regelmäßig finanziell. $8 \%$ der Frauen pflegen ihre Eltern oder Schwiegereltern. Nach der jüngsten demographischen Entwicklung in Europa müsste demnächst ein Enkelkind vier Großeltern versorgen.

\section{Anmerkung $\mathbf{9}$ \\ Nähe}

Die räumliche Nähe zwischen den Generationen hat sich kaum verändert. Nach einer Studie des deutschen Familienministeriums leben zwei Drittel der Jungen am Ort der Alten, $12 \%$ sogar im selben Haus.

\section{Anmerkung 10}

Unter uns ist's immer am schönsten

Kinder und Eltern fühlen sich am wohlsten, wenn Besuch kommt - so eine Studie der Universität Fribourg (Schweiz).

\section{Anmerkung 11}

Die Supermama

Kinder von Hausfrauen schneiden in der Schule schlechter ab, als Kinder von berufstätigen Müttern, so eine Untersuchung des Berliner Max -PlanckInstituts. Es kommt nicht auf die Quantität der gemeinsamen Stunden an, sondern auf die "Quality Time", wie es amerikanische Wissenschaftler nennen. Mittlerweile gelten auch in Deutschland

«Karrierefrauen» (gemeint sind Frauen, die es sich erlauben auch zu arbeiten) nicht mehr als «Rabenmütter».

\section{Schlussbemerkung}

Partnerwahlen, und dies schließt eine Trennung nicht aus, wollen frei getroffen werden. Das war -und istnicht immer so.

Traditionell ist die Ehe ein Wirtschaftspakt, die Liebe eine Idee der Romantik.

Der oft gepriesene «Familienzusammenhalt» konservativer Kulturen gründet sich leider oft auf Gewalt. Momentan steigt in Deutschland mit dem Anstieg der Arbeitslosigkeit auch die Sehnsucht auf Familie. 